\title{
Personal choice: strategic life decision-making and conscience
}

\author{
Liubov Pomytkina $^{1 *}$, Arthur Gudmanian ${ }^{1}$, Olena Kovtun ${ }^{1}$, and Serhii Yahodzinskyi $^{1}$ \\ ${ }^{1}$ National Aviation University, 03058 Kyiv, Ukraine
}

\begin{abstract}
The article highlights the problem of subjective choice in making strategic life decisions and its correlation with conscience. The study describes the nature of strategic life decision-making, determines types of strategic life decisions, discloses the essence of human experiences associated with strategic life decision-making, and provides results of empirical research. Decision-making, as viewed in scientific psychological practice, is an intense cognitive process for which a human actor should be prepared to perform, drawing upon a full range of knowledge, abilities, skills, and personal qualities. Decisions, though varied by type and degree of difficulty and complexity, are united by choice - that is the individual's choice as such. Crucial moments of decision-making may affect people in myriad ways. This article analyses the experiences of such human actors while making strategic life decisions, defined by scientists to mean outstanding, fateful, associated with great responsibility, with their leading role in human living space, and formation of a person's way of living. Emotions and emotional responses occupy a space of paramount importance in this type of decision-making. As strategic life decisions are cognizantly and predominantly made mainly in late adolescence, the authors present summarized results of the empirical research that was carried out for several years among students enrolled in a variety of higher educational institutions within Ukraine.
\end{abstract}

\section{Introduction}

For many people decision-making can be an exciting, if not 'stressful' moment. For some, it is a moment of future success and triumph, however, for others decision-making can resemble long and painful experiences. Why is it a moment, not hours, days or years of suffering? What causes suffering and torment of the wrong decision?

Decision-making always involves a single choice made among available alternatives. When a decision must be made but all the alternatives are irrelevant or undesirable, a person may experience certain emotions that may well cause suffering or torment.

The aim of the article is to find out how young people in the modern world make the important decisions for their future. According to the research aim, the following tasks were set: 1) to study the nature of strategic life decision-making and determine types of strategic life decisions; 2) to show interrelation of decision-making and conscience; 3) to present

\footnotetext{
*Corresponding author: sophist@nau.edu.ua
} 
empirical data on correlation of strategic life decision-making with personal qualities of youth, their choice of strategies for achieving objectives and reflection.

\section{Etymology of decisions}

First of all, let us consider the difference between a choice and decision-making. A choice is viewed as a process (short or long). Decision-making is a moment of great import for the person who has made it. It is also necessary to differentiate at least three types of decisions: a) cognitive emotionally tense; b) vitally important; c) strategic life.

In the first case, a person must make a choice and take the only right decision in a very short period. This often happens in the professional activity of operators, pilots, divers, astronauts, and military men, as these professionals often operate in stressful conditions. The tension of the decision-making moment is caused by extraordinary responsibility the actor assumes (for ourselves, for other people, for the task being done, etc...), and is often compounded by the lack of time to make such an important and critical decision.

In the second case, a vitally important decision is made in the event where primordial vitality is concerned. For example, when a person sees a person drowning or someone on fire, the actor's decision whether to extend or withhold aid is vitally important. Firstly, it is important for the person in distress i. e, the hope for salvation or the assurance of their demise. Secondly, it is important for the very actor, since the decision must be properly weighed and taken in accordance with personal priorities and values, (e.g. potential risks, or benefits, or moral beliefs). These vitally important decisions can also be attributed to as emotionally tense in that a decision may be required quickly.

In case of making strategic life decisions, to which scientists refer decisions such as professional self-determination, choice of a marriage partner, or formation of personal attitudes, beliefs and relationships [1-3], the emotional component becomes the most influential. A person may experience stress and uncertainty for quite a long time (after such decisions are made). They may feel burden of responsibility for their own life and for effects on the lives of the closest people in his or her immediate milieu. The consequences can be severe, as the decision taken and the strategies employed for its realization shape the construction of this person's future.

In all three cases, the process of decision-making develops gradually in accordance with certain, scientifically described stages, alongside the actuation of dominating psychological mechanisms within these different stages.

\section{Strategic life decisions}

In the following paragraphs we will focus on strategic life decisions. This type of decisionmaking usually takes a long time (sometimes even several years!) and is associated with powerful emotional and volitional efforts, and may be accompanied by certain experiences. In our opinion, the aforementioned observations necessitate further scientific research of this phenomenon and its nature.

Scientists define strategic life decisions as decisions of outstanding, fateful character. They are associated with great responsibility, play leading role in human living space, and influence the formation of person's walk of life (way of living) [4]. A strategic life decision can be an act of personal choice, or can be determined by external circumstances (public opinion, political situation, etc.). Strategic life decision-making is, firstly, a process of extreme responsibility; secondly, it is associated with projecting long-term intervals of human life; and thirdly, it is highly influenced by values, feelings, and emotions. Strategic life decisions are aimed at choosing: values and ideals, a loved one, and professional 
activity; work, friendship and love [5]; achievements in career or professional activity, establishing relationships in the society and in the personal and family space; attitudes to the world of external objects or things, towards other people, and of the self. Thus, strategic life decisions include decisions on professional self-determination, choice of a marriage partner, or formation of personal attitudes, beliefs and relationships, among other things.

Analyses reveal that the most sensitive age for making strategic life decisions is late adolescence (18-25 years), which is the typical age for students considering post-secondary education. Students within this age range age are generally characterized by creativity and strong desire for personal fulfillment. Indeed, scientists have found it to be the most significant period in human life. In late adolescence a person usually develops his or her ultimate set of values, which project influence in shaping the main directions of selffulfillment for other stages of life [4].

Analysis of scientific works revealed that strategic life decision-making follows the following stages: 1) awareness of the importance of goals; 2) creative search of new alternatives or options, and evaluation of their desirability; 3) making a preliminary decision; and 4) making an ultimate strategic life decision $[3,4,6,7]$.

Thus, by definition strategic life decisions cannot be made by a person per saltum. Such decision requires lengthy deliberation and consideration, and as such long time, may cause strong feelings of uncertainty, regret, or second-guessing.

\section{The experience of decision-making in the work of researchers}

In the 1960's, some research on ambiguity tolerance-intolerance were conducted (Tolerance Ambiguity Scale), the results of which were summarized in the relevant questionnaire [8]. Tolerance for ambiguity was considered by scientists as an individual predisposition to evaluate uncertain situations as desirable or as threatening. It is a person's ability to accept conflict and tension arising in situations of duality, to resist incoherent and contradictory information, to accept the unknown, and to feel comfortable in the face of uncertainty [8].

Tolerance is viewed as a personal characteristic and is studied from the perspective of psychological stability, within a system of values, personal settings, and a set of various individual properties [9]. Tolerance for ambiguity is associated with high emotional intelligence and high self-efficiency. Conversely, intolerance is associated with low academic intelligence and low self-efficiency. Additionally, through numerous studies, researchers have noted the emergence of anxiety, and therefore certain experiences as predictor of individual intolerance to ambiguity.

Janis and Mann in their research of extreme activities, viewed a decision-making process as one full of a person's experiences [10]. In particular, decision-making is defined as an emotionally intense cognitive process. Scientists sought to study the deepest psychological mechanisms of decision-making, which they associate with motivational conflicts, clashes of emotive / emotional tendencies, and emphasize subtle shades of person's emotional processes. Researchers also tried to examine choice and decisionmaking without applying formal approaches typical for this branch of science. They paid great attention to the question why it is difficult for people to make decisions, and analyzed, above all, the motivational side of strategic life decision-making.

It is important that they present decision in the context of temporal perspective, emphasizing not instantaneity but duration of the process, and its division into several stages. However, the number of stages and criteria for division are not the same. In particular, Janis and Mann associate decision-making with risk assessment and commitment and differentiate the following five stages, stating certain experiences of a person associated with doubt and fear:

1. Assessment of the problem - What happens / will happen if I do nothing? 
2. Analysis / consideration of options - Will the chosen course of action itself allow solve the problem? Have I considered a sufficient number of options?

3. Evaluation of options - What is the best option? What requirements does this option demand?

4. Notification associates of the selected course of action, adoption of commitment - Do I need to notify the decision to others?

5. The decision despite the risk - Is the risk high if I change nothing?

The list of stages indicates the social context of decision-making, meaning that implementation of the decisions made will occur under the pressure of obligations taken and in the presence of other people. However, a person is not always ready to share every decision with others. Some decisions (especially strategic life) people can keep a secret even from close friends, until realizing them in practice. For instance, a decision on determination of personal attitudes, or choice of a marriage partner a person may keep a secret until he/she is eventually certain that the decision is final or reasonable.

An examination of contemporary European and American scientists confirm the presence of experiences while decision-making in different social situations: while choosing decisional conflict styles among high school students [11]; in self-examination of stimulant-dependent and opiate-dependent individuals while decision-making about stimulants usage [12]; while decision-making on relations between an individual and a society [13], etc.

K. Arnold in her book "Small Move, Big Change: Using Microresolutions to Transform Your Life Permanently", outlines specific interrelations between routine daily decisions, and decisions on a larger scale [14]. The author explains how "microresolutions" - tiny behavioral modifications that can be incorporated into daily habits - are the key to making lasting changes for life. Since these are microresolutions, they can be quite easily estimated, fully managed, and effortlessly complied with. This allows a person to feel like a winner, get more organized, and self-improve every single day, and eventually achieve his/her major goals. The book explains how to look at existing tendencies, recognize the actions and external cues that trigger a behavior, and re-wire routines to turn a new and improved behavior into a habit, all without using much willpower. However, the book lacks description of psychological techniques and practical guides that allow achieving the desired condition.

"Mental turnover" in decision-making. What happens in the human psyche when it is involved in decision-making? Decision-making is known as a complex hierarchical process of human mental activity, during which initial uncertainty of a problem situation is reduced [7]. To make a decision means to select a specific purpose and course of action, and to give that course a specific advantage over others $[3,15]$.

Ukrainian psychologist M.Ya. Grot studied interdependence of decision-making and personal characteristics of an individual [16]. Grot's key ideas formed the basis of many theories of Western scholars and developed the major paradigm of the twentieth century world psychology. Grot described the decision-making process and outlined its specific complexity, which he called "mental turnover" as a basic mechanism of human mental life and a basic unit of mental activity [16]. Mental turnover is characterized by a unity of sensory, motor and converting components and starts with external movements and impressions that turn into inner impressions or feelings which, in turn, generate a sense of internal volitional aspirations, culminating with external movements and actions.

The scientist Grot M.Ya. defined mental turnover as a unit of mental activity, as a holistic / integral process of intensification of perception, emotion, intellectual and volitional activity of a person [16]. Thus, mental turnover is a cyclic process that determines the sequence of emotional and intellectual activity of a person, prior to his/her taking a preliminary decision, which, after receiving additional information and reflection 
of new alternatives, is specified. This cycle can repeat until an ultimate decision is made, evoking volitional efforts for its fulfillment.

Is it logical, then, to speak about the ability to make an ultimate strategic life decision if the human psyche, after getting new information, starts a new cycle involving perception, analysis, comparison, generalization, awareness - that is the whole complex of mental activities? In our opinion, it is more correct to call this phenomenon "decision taken at a certain time." Even when the decision is made, a person still cannot sleep easily, rethinks, and changes his / her mind. What disturbs this person? What makes him / her feel restless? Asking such questions, we can hear potential answers like that: I feel thoughts of other people, and they disturb / confuse me... Here a new question arises: are these thoughts, in fact, the thoughts of other people or my own, personal thoughts. What emotions and experiences does a person have when he / she feels gaze of his or her own conscience?

At the end of the XIX th century, W. James conducted in-depth research of the human consciousness, creating his famous model, which to this day is influential in the cognitive psychology of consciousness [17]. James dedicated considerable attention to the decisionmaking process as a model of choice. The scientist believed that the choice is determined by mind, will, accidental impulse and fear, highlighting five types of decisions:

1. A reasonable / rational decision. An individual considers arguments for and against a certain course of action and chooses one. Arguments are rationally weighed and a decision is made with a clear sense that a person is free.

2. A volitional decision. An individual focuses on the sensation of "internal efforts". This is a "slow, deep movement of will". This option of decision is quite rare, because most human choices are made effortlessly.

3. A drifting decision: In this case there are no decisive arguments in favor of a particular choice; every argument seems good, and an individual is experiencing fatigue or frustration of his / her decision. It seems that the decision chosen enables a drift in a direction that is externally influenced.

4. An impulsive decision: An individual feels unable to make a decision, and the choice can become random. However, the answer comes from inside, not outside, as in the previous case. An individual perceives him- / herself as the one that acts automatically and often impulsively.

5. Decisions caused by change of views. This decision often occurs suddenly and is the result of some important external experience, or internal state (e.g., sadness or fear). It leads to a significant change of what a person wishes or aspires.

The views of the scientist (W. James) are important for our research, because this differentiation of decisions enables us to come closer to understanding of those processes and experiences, which happen within an individual and, in particular, those that involve mental and volitional processes, random impulses and affective reactions fear.

\section{Human experiences}

Let us consider the psychological content of human experiences. As it is known, experience in psychology is considered in three meanings that together make understanding of this phenomenon. Experience is defined: 1) as any emotionally colored state of a person and the phenomenon of reality directly represented in the mind as an event of his / her own life; 2) as aspirations, desires and wishes that reflect in the individual consciousness the process of selecting motives and goals of future activities and thus contribute to person's conscious attitude to events happening in his / her life; 3) as a form of activity that occurs when a person is unable to achieve leading motives of his / her life, when there is a collapse of ideals and values; it is manifested in turning a person's psychological world and aimed at rethinking of his / her existence. 
All of these forms of experience act as internal signals by which a person realizes a choice of possible alternatives, makes decisions, and regulates his or her own behavior. As a special form of activity, experiences allow a person to endure severe events in critical life situations, and gain meaningfulness of existence due to revaluation of values [15].

So, experience is a form of expression of person's attitude to the object, to the situation, to another person, and to self. It is an emotional and sensory reflection of person's attitude to the surrounding world.

\section{Psychological mechanisms of experiences}

Human experiences are primarily caused by the mechanisms of reflection. Reflection is known as a process of a person's self-understanding of internal mental acts and states. R. Dekart identified reflection with the ability of an individual to focus on the content of his or her own thoughts, abstracting from everything external or corporal [18]. J. Locke understood reflection as a special source of knowledge, as an internal experience opposite to external, based on the senses [19]. But reflection cannot be limited to the individual's self-knowledge or self-understanding; it also presupposes an individual's awareness of how he / she is perceived and evaluated by others and by the community. It is a kind of cognitive process, during which a person becomes the object of his or her own observation: thoughts, feeling and analyses of his or her own mental states.

In psychological dictionaries, reflection is defined as intellectual (rational) process aimed at analysis, understanding and cognition of self (own actions, behavior, tasks, speech, experience, feelings, states, abilities, character, relationships with and attitude to others, life objectives) that is conceptually, procedurally and functionally linked to introspection, retrospection and self-consciousness. We believe that in making strategic life decisions it is worthwhile to emphasize and differentiate between intellectual and personal reflection.

Scientists define intellectual reflection as the ability to select, analyze, and correlate one's own actions with the substantive work. In the process of decision-making intellectual reflection is necessary for a person to understand the basis of own mental activity. Intellectual reflection manifests itself through complementary mechanisms of generation and control. It provides general regulation of subject-operating transformations of the content of decision-making process: the mechanism of generation provides the use and transformation of integral guideline of mental activity - its semantic gestalt (models, tools, charts), and the control mechanism - specification and implementation in the thinking already existing integral functional elements of its content.

Personal reflection is considered by scientists in one and the same synonymic row with the concept "self-reflection," which provides self-organization and self-mobilization of a person in different conditions of his / her existence [20,21]. Scientists also studied personal reflection in the process of self-regulation when an individual is at the same time an object of reflection and its subject, who regulates own actions and deeds [1]. Personal reflection provides an individual with the ability to reflect and interpret their own motives, predict consequences of actions and deeds to self and others, and coordinate personal goals and behavior with the means of achieving them [20].

It is the personal reflection that encourages individual self-determination, particularly in three key areas of life: determination of personal attitudes, professional self-determination, and choice of a marriage partner.

Personal reflection in the process of strategic life decision-making manifests itself in person's self-reconsidering own anima which is realized through directing cognition at self, analyzing own inner world, evaluating own qualities and states. When a person forecasts future activity in every moment of life, regulates his or her own behavior and deeds or 
chooses objectives, he/she always relates their own potential with understanding how important and significant for him / her are the requirements and conditions of strategic life decision-makings (in other words, self-reflects). Thus, the unity of intellectual and personal reflections in the strategic life decision-making contributes to their adequacy and is essential for the rising efficiency of preparing people to perform the aforementioned actions.

Depending on directions of assessment and reassessment of personal contents, an individual may experience different types of personal reflection: a retrospective type of personal reflection (assessment and reassessment of the past self-concept); a situational type of personal reflection (assessment and reassessment of the real self-concept); or a prospective type of personal reflection (assessment and reassessment of the future selfconcept).

As researcher point out, the leading criterion for the existence of personal reflection is "reflective analysis," which leads a person to gain new knowledge of self as a subject of life, and allows differentiation of three levels of self-reflection: fixed, understated, and balanced. The balanced level is considered the most effective in self-knowledge, selfassertion, and self-development of a person.

However, the availability of a reflection mechanism does not guarantee evoking a person's emotional experiences in either a positive or negative way. Rather, we should speak about a complex set of mechanisms that involves, according to the stages of the decision-making, motivational, emotional, volitional mechanisms [4].

\section{Decision-making and conscience}

What worries a person when trying to make a decision? What haunts us when a decision seems to have already been made, when there seems to be uncertainty as to the best course of action?

A number of questions may arise:

- Have I made the right decision?

- Has everything been taken into account?

- What will other people think of my decision? What will they say? How will they treat me?

- What impact will it have on my future? On someone else's future?

All the experiences felt both during the decision-making process and after it, are evoked not only by the reflection mechanism but also by an integral mechanism, often called conscience.

The notion of "conscience" is defined in philosophical dictionaries as a "moral category that reflects the highest form of person's capacity to moral self-control." Unlike motive (a sense of duty) conscience also comprises self-evaluation of the actions taken before because of person's self-understanding own responsibility to others and society. Conscience binds a person not only to gain self-respect through own actions, or to develop a sense of honor and personal dignity, but also to fully dedicate him/herself to the community, society, and humankind. Moreover, conscience implies the ability of a person to be critical about one's own and other people's opinions, the needs of the society, the shared or individual responsibilities for one's own actions insofar as it may affect society at large.

Conscience is an ability of a person that is brought up by the society. It is determined by the degree of historical development and by social position of a person in the objective conditions into which he/she is placed. Being an active back reaction of a person to the requirements of the society and its progressive development, conscience is viewed as an internal engine of person's moral self-improvement and a stimulus for his / her active and practical approach to the reality. Conscience can occur both in the form of person's rational 
understanding of the moral significance of own actions, and in the complex of emotional experiences (feelings of remorse). Developing the conscience of a person is one of the most important aspects in the formation of human morality. Thus, the mechanism of conscience manifests itself in emotional experiences and it is due to the conscience that human experiences evoke strong emotion.

Emotions are viewed as mental reflections of direct passionate life experiences, inducing events and situations; as relatively brief conscious experiences characterized by intense mental activity coupled with varying degrees of pleasure or displeasure. Human emotions are referred to as processes of internal control of behavior. As S.L. Rubinshtein points out, a person "experiences what happens with him/her and what he / she does; demonstrates in some way his/her attitude to the surrounding. The experience of this attitude to the surrounding makes a rich and various area of human emotions and feelings" [6]. Thus, emotions are treated as a specific type of reflection, as a kind of unity of reflected content and experiences, which implies attitude of a person to his / her own reflection.

American psychologist C.E. Izard indicated that, "in the process of conscience formation - the process of moral development of an individual - all emotions play a certain role ... But the main role belongs to the guilt - the most important of all emotions" [22]. The theory of differential emotions considers the emotion of guilt as one of the most basic. The concept of guilt has come a long way in evolutionary development: every sociocultural unity (a family, a church, etc.) based on certain ethical and moral principles forms conditional signals of fault: they set certain standards of conduct and try to convince younger generation to accept them. These postulates (moral and ethical principles) make up a cognitive component of conscience. Mature conscience and related emotions form the affective-cognitive structure that evaluates every step of an individual to its compliance with moral principles. The experience of guilt, to a greater extent than fear, influences a person and his or her conscience, in Izard's estimation.

Izard assures us that while the experience of guilt focuses a person's attention on the source of guilt, it does not let go without remorse or excuses. Furthermore, the source of fear makes run and releases to a safe distance from it [22]. The ability to balance on the border that measures conformity dictated by fear and responsibility, inspired by a sense of guilt, can be seen as evidence of a mature conscience and moral behavior. The sense of responsibility makes a nucleus of the structure of conscience: it focuses on the awareness of guilt and at the same time facilitates the selection of the behavior style that reduces the likelihood of intense feelings of guilt. Responsibility is an important component of willpower. It reflects certain social, moral and legal attitudes of the individual to the group, community or society as a whole, and is characterized by fulfilling moral duties and legal norms. In strategic life decision-making, responsibility characterizes abilities and capacities of a person to act as a subject, set purposes consciously, and carry out decisions -in essence, to make the right choice [23-26].

In analyzing the psychological content of experiences in strategic life decision-making, we conclude that the conscience of a person determines the range of emotions and feelings, especially those of doubt, guilt and fear, and is mediated by personal qualities such as responsibility and perseverance, among others. It enables us to speak about the emotional and volitional sphere of personality, for volitional efforts (willpower) allow a person to come to a conclusion, to stop experiencing uncertainty and make the right decision (or correct a previous one). Personal volitional qualities enable a person to realize and implement strategic life decisions to develop personal attitudes (view of life), professional self-determination, and choice of a marriage partner.

The importance of willpower development is discussed at length in contemporary European and American studies. K. McGonigal, a professor at Stanford University, in her book "The Willpower Instinct", outlines the techniques of achieving strategic life goals 
[27]. McGonigal has conducted an in-depth study of human willpower and its basic qualities. Summarizing the results of current research in the field, McGonigal explains how to replace bad habits with useful ones, how not to postpone the case until the last minute, and how to concentrate and cope with stress. McGonigal considers that it is surprisingly easy to develop willpower, inasmuch as all that is necessary for this is a belief in one's own potential. According to her, a person experiences conflicts and emotional stress due to insufficiently developed willpower, for the human brain tends to conflate the promise of reward with a guarantee of happiness.

\section{Results of empirical research}

Since the process of strategic life decision-making primarily concerns the youth, over several years we conducted empirical studies of a number of students enrolled in higher educational establishments in Ukraine. The study focused on finding out how young people in the modern world make the important decisions for their future.

The research of willpower, in particular a number of volitional powers, showed that decision-making is determined, first of all, by such personal qualities as independence $(r=$ $0,82$, at $p \leq 0,01)$, resolve $(r=0,57$, at $p \leq 0,01)$, commitment $(r=0,46$, at $p \leq 0,05)$ and desire to forecast the future $(r=0,47$, at $\mathrm{p} \leq 0,05)$. In particular, the highest correlation of the quality "independence" is consistent with the detected specificity of those decisions that are vitally important, and therefore responsibility for their consequence's rests not on parents or referent environment, but on a young person's internal understanding of selfagency.

Table 1. Fragment of the factor matrix of correlation connection between student's personality characteristics and their readiness for making strategic life decisions $(n=850)$.

\begin{tabular}{|c|c|c|c|c|c|c|c|}
\hline & Indecisive & $\begin{array}{c}\text { Depends } \\
\text { on } \\
\text { circumsta } \\
\text { nces }\end{array}$ & Decisive & $\begin{array}{c}\text { Inde- } \\
\text { pendent }\end{array}$ & $\begin{array}{c}\text { Purposefu } \\
\text { I }\end{array}$ & $\begin{array}{c}\text { Aspires to } \\
\text { predict the } \\
\text { future }\end{array}$ & $\begin{array}{c}\text { Level of } \\
\text { readiness }\end{array}$ \\
\hline Indecisive & - & 0.12 & $-7.17^{* *}$ & -0.43 & -0.44 & -0.17 & $-0.519^{* *}$ \\
\hline $\begin{array}{c}\text { Depends on } \\
\text { circumstances }\end{array}$ & 0.12 & - & 0.03 & -0.42 & $-0.526^{*}$ & $-0.540^{*}$ & $-0.586^{* *}$ \\
\hline Decisive & $-0.717^{* *}$ & 0.03 & - & 0.41 & $0.462^{*}$ & 0.23 & $0.569^{* *}$ \\
\hline Independent & -0.43 & -0.42 & 0.41 & - & 0.44 & 0.34 & $0.817^{* *}$ \\
\hline Purposeful & -0.44 & $-0.526^{*}$ & $0.462^{*}$ & 0.44 & - & $0.705^{* *}$ & $0.464^{*}$ \\
\hline $\begin{array}{c}\text { Aspires to } \\
\text { predict the } \\
\text { future }\end{array}$ & -0.17 & $-0.540^{*}$ & 0.23 & 0.34 & $0.705^{* *}$ & - & $0.467^{*}$ \\
\hline $\begin{array}{c}\text { Level of } \\
\text { readiness }\end{array}$ & $-0.519^{* *}$ & $-0.586^{* *}$ & $0.569^{* *}$ & $0.817^{* *}$ & $0.464^{*}$ & $0.467^{*}$ & - \\
\hline
\end{tabular}

Note: ${ }^{*}-$ the connection is significant at the level $\mathrm{p} \leq 0.05 ;{ }^{* *}-$ the connection is significant at the level $\mathrm{p} \leq 0.01$.

The analysis of the correlation matrix made it possible to construct a hierarchy of personality characteristics on the measure of connection and significance in the process of students making strategic life decisions (see Fig. 1). Thus, making strategic life decisions by students is determined by the actualization of their personal qualities, including independence, decisiveness, purposefulness, aspiration to predict the future. However, the 
development of these qualities in students corresponds to the average and lower average levels.

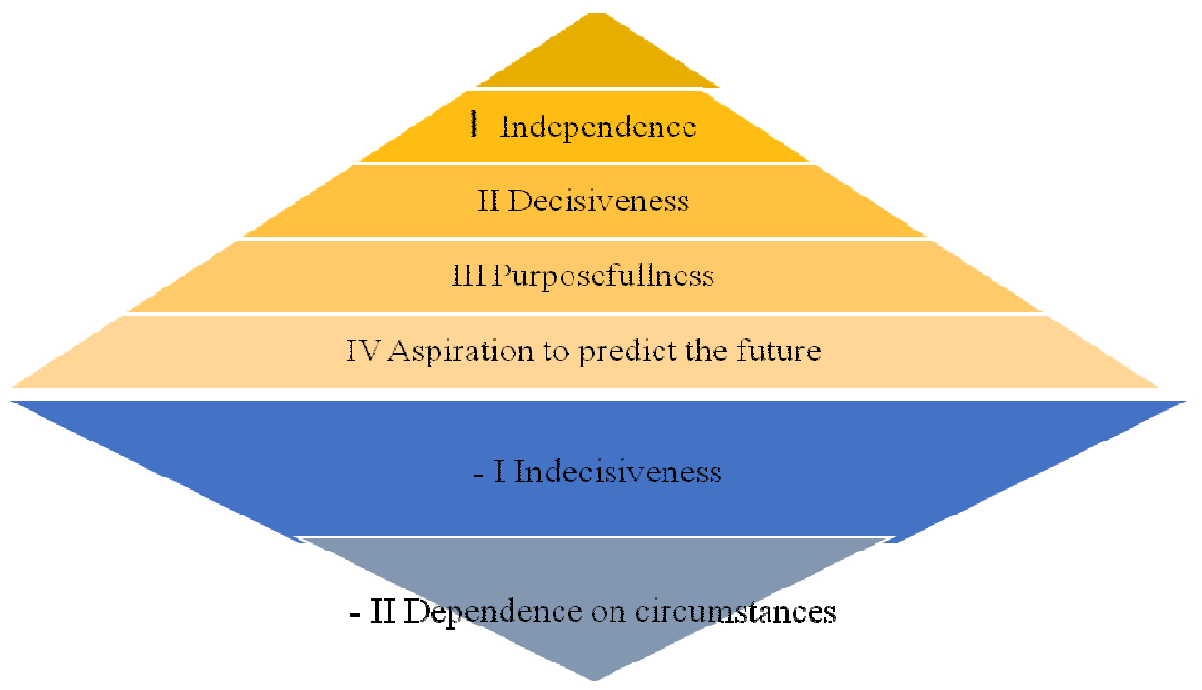

Fig. 1. Hierarchy of personality qualities of students, connected with readiness to making strategic life decisions.

Diagnostic of strategies for achieving objectives showed that most students choose a passive strategy $(38.9 \%)$, which is characterized by excessive caution, renunciation of leadership, and social closure of personality. An active and flexible strategy (33.3\%), which constitutes a significant minority, is characterized by a combination of activity with communicative "diplomacy". The dominance of passive strategy is consistent with on the "wait-and-see" attitude of today's youth, who seem indifferent to the majority of public life. This may explain why students lack personal readiness to make strategic life decisions.

Research of students' reflection with prolonged decision-making, showed that $39.4 \%$ of respondents demonstrated below the average level, which is characterized by insufficient ability to analyze and consider own actions and make important decisions. The students were not able to adequately assess themselves and other people, and thus understand how they are assessed by others.

Prospective reflection was determined as a dominant type among young people $(62.5 \%)$. On the one hand, this proves the efficiency of the function of analysis of future activity, behavior and prediction. On the other hand, the low level of situational (6.2\%) and retrospective reflection (9.4\%) prevents students from making sufficient analysis of previously performed actions; does not allow assessing motives, reasons and background of the happened and causes of errors, and therefore impedes their constructive cooperation and effective decision-making in the future.

We also studied personal qualities of the students, such as tolerance for ambiguity (was characteristic of $37.8 \%$ responders). The results showed that today's young people are mostly intolerant to uncertainty; they feel constant stress due to ambiguity, uncertainty and multidimensionality of choices in different situations. Striving for clarity and transparency leads to the tendency that students respond to prolonged uncertainty with anxiety and experience.

Findings of the conducted narrative study proved that students experience constant anxiety $(63.7 \%)$ due to long-term uncertainty in making ultimate decision on determination of personal attitudes (view of life), professional self-determination, and choice of a marriage partner. This produces emotional instability and affective reactions. 
General results of empirical studies have shown a lack of readiness of students to adequate strategic life decision-making.

\section{Conclusions}

Thus, subjective choices made in the process of strategic life decision-making, is characterized by certain emotional experiences. Experiences felt by a person while strategic life decision-making (regarding determination of personal attitudes (view of life), professional self-determination, and choice of a marriage partner) are caused primarily by their features, such as prolonged duration, increased responsibility for their impact on the entire life and presence of the previous decision. The main factor of the experience is conscience, which may evoke feelings of guilt, doubt, fear and inadequate responsibility while reflection.

Thus, the main psychological mechanisms of strategic life decision-making are represented by mental turnover as a unit of mental activity; intellectual and personal reflection as general mechanism of consciousness; and conscience as a factor of experience in various forms of emotional and volitional reactions and feelings of the individual.

We may conclude that the psychological mechanisms discussed above in their unity cause the ability of an individual to regulate personal experiences in making strategic life decisions and solving crucial life problems. At the same time, these psychological mechanisms are general in nature and are not related to such determining characteristics as age, leading needs, social status of an individual, and others. Each of them is actuated during the experience depending on the content of strategic life decisions themselves.

\section{Discussion}

Conducted theoretical and empirical research does not make a claim for exhaustive results. Disputable remain questions regarding the possible impacts of society, environment, advertising and Internet networks on the human involved in the decision-making process.

Therefore, future research will be dedicated to the analysis of psychological principles on which personal readiness of an individual to make strategic life decisions is developed. This will help to differentiate from the general array of psychological mechanisms, i.e. those mechanisms that are the most characteristic for the aforementioned decisions and experiences. Unfortunately, researches of experiences of young people during prolonged decision-making are currently limited due to lack of psycho diagnostic tools for determining their psychological content, depth and intensity. However, understanding the importance of this issue, we are working to develop research methods that will be outlined in further publications.

\section{References}

1. K.A. Abulhanova-Slavskaya, Strategiya zhizni (Life Strategy), 299 (Moscow, 1991)

2. A. Adler, Nauka zit' (Science live), Port-Royal, 134 (Port-Royal, Kiev, 1997)

3. G.O. Ball, Oriyentiry suchasnogo gumanizmu (v suspilniy, osvitniy, psyhologichniy sferah) (Landmarks of modern humanism (in the social, educational, psychological areas), 172, (Vidaves Oleg Zen, Kiev-Rivne, 2007)

4. L.V. Pomytkina, Psyhologiya prynyattya osobististyu strategichnih zhittyevih rishen: monografiya (Psychology of personality strategic life decisions: monograph), 381 (Kafedra, Kiev, 2013) 
5. A. Adler, Human Development 3, 184-200 (1968)

6. S.L. Rubinshtein, Osnovi obshey psihologii (Fundamentals of General Psychology), Piter, 720 (Piter, Saint-Petersburg, 2000)

7. A.K. Tikhomirov, Psihologicheskie mehanizmi seleobrazovaniya, Nauka, 570 (Nauka, Moscow, 1977)

8. S. Budner, Journ. of Personality 30, 29-40 (1962)

9. T.V. Kornilov, M.A. Chumakova, Experimentalnaya psihologiya, 1, 92-110 (2014)

10. I. Janis, L. Mann, Decision Making: A Psychological Analysis of Conflict, Choice and Commitment, The Free Press (The Free Press, New York, 1977)

11. A. Di Fabio, D. Blustein, Journal of Career Assessment 18(1), 71-81 (2010)

12. H. Gorodetzky, B.J. Sahakian, T.W. Robbins, K.D. Ersche, Psychiatry Research 186, 2-3, 437-440 (2011)

13. E. Sari, World Applied Sciences Journal 3(3), 369-381 (2008)

14. K. Arnold, Mikroresheniya. Provereniy put $k$ dostigheniyu bolshih seley (Microdecisions. Experienced way to achieve great goals), 288 (Mann, Ivanov I Ferber, Moscow, 2014)

15. F.E. Vasilyuk, Psihologiya perezivaniya (analiz preodoleniya kriticheskih situasiy) (Life experience (analysis of overcoming critical situations), 200 (Moscow, 1984)

16. M. Ya. Grot, $K$ voprosu o reforme logiki. Opit novoy teorii umstvennih prosesov (On the question of the reform of logic. Experience a new theory of mental processes), Leipsig, 349 (Leipzig, 1882)

17. R. Frager, J. Fadiman, Lichnost. Teorii, uprajneniya, experimenti (Personality. Theory, exercises, experiments), 704 (Praim-EVROZNAK, Saint-Petrsburg, 2006)

18. R. Dekart, Raziskanie istini (The search for truth), 286 (Azbuka, Saint-Petrsburg, 2000)

19. J. Locke, An Essay Concerning Human Understanding in Focus (Routledge, 2000)

20. I.D. Beh, Vid voly do osobistosty (The will of the individual), 202 (Ukraina-Vita, Kiev, 1995)

21. R.U. Emerson, Doverie $k$ sebe (Trust in Me), 21-43 (Piter-Press, Saint-Petrsburg, 1992)

22. K.E. Izard, Psyhologiya emosiy (Psychology of emotions), 461 (Piter, Saint-Petrsburg, 2011)

23. I. Dzhanis, L. Mann, Prinyatie resheniya. Chelovecheskiy factor (Decision-making. Human factor), 81-104 (Transport, Moscow, 1986)

24. M.Ya.Grot, Vibrani psihologichni tvory (Selected psychological works), 296, (Vidavnitsto NDU im.M.Gogolya, Nizhin, 2006)

25. P. Lyubov, European Applied Sciences 5, 155-157 (2013)

26. L.V. Pomytkina, 2016 IEEE 4th International Conference "Methods and Systems of Navigation and Motion Control (MSNMC)", 232-236 (2016)

27. K. McGonigal, Sila voli. Kak razvit I ukrepit (Strength of will. How to develop and strengthen), Mann, Ivanov I Ferber, 590 (Mann, Ivanov I Ferber, Moscow, 2014) 